\title{
To tell a story, you need a protagonist: how dynamic interactive mediators can fulfill this role and foster explorative participation to mathematical discourse
}

\author{
Anna Baccaglini-Frank ${ }^{1}$
}

Accepted: 29 October 2020 / Published online: 9 January 2021

(C) The Author(s) 2021

\begin{abstract}
This paper focuses on students' mathematical discourse emerging from interactions in the digital environment GeoGebra, in which one can construct virtual objects that realize mathematical signifiers and then interact with them. These virtual object realizations can become dynamic interactive mediators (DIMs) that influence the development of the learners' mathematical discourse. In this case study, I analyze in fine detail the discourse developed by two dyads of students in response to an unfamiliar interview question. One dyad came from a class in which GeoGebra was not part of classroom practice and included students who, according to the teacher's evaluation, were standard-to-high achieving. The other dyad was from a generally demotivated and low-achieving class in which GeoGebra had become part of classroom practice. The analyses, focused especially on the lowachieving dyad, are guided by the question of how DIMs shaped these students' discourse. According to the analysis, these students ended up succeeding where standard-to-high-achieving peers did not. Moreover, the detailed analysis of the ways in which the DIMs supported this dyad's learning showed mechanisms that may be general rather than specific to this one case. This suggests that appropriate integration of DIMs into the teaching and learning of high school algebra can be beneficial for low-achieving students.
\end{abstract}

Keywords Abstract objects · Discursive approach · Dynamic interactive mediators (DIMs) Explorative participation $\cdot$ Functions $\cdot$ Mathematical discourse $\cdot$ Ritualistic participation

Anna Baccaglini-Frank anna.baccaglinifrank@unipi.it

1 Department of Mathematics, University of Pisa, Pisa, Italy 


\section{Introduction: how digital technology can shape students' mathematics learning}

These days, more than half a century after their first appearance, the potential of digital learning environments to enhance students' mathematical achievement is generally recognized. Decades of research have brought ample evidence for their educational power. Less clear is the issue of how the use of technology affects the process of learning. Much research is still needed to answer such questions as How and why does computer mediation turn mathematical rituals into genuine explorations? or How do specific uses of digital technologies shape the learning experience of students with different needs and different histories as mathematics learners?

The aim of this paper is to address these latter issues by conducting in-depth analyses of computer-mediated mathematical discourse. While focusing on mathematics learners with long histories of failure, I will try to go beyond a mere corroboration of the claim that for them, digital media hold a special promise. Instead, I will be asking how particular types of computer interactions become integrated into the process of learning, thereby ushering the hitherto excluded student into full-fledged, meaningful participation. More specifically, I will be investigating the ways in which interactive graphical software, with its special capacity to bring intangible mathematical abstract objects, such as functions, to life, helps the learner to act in a well-reasoned, explorative, and eventually successful manner. The perspective taken in this study, along with its findings, will also lead to an exhortation to look critically at, and possibly revise, our thinking about learning difficulties.

\section{Research on digital mediation of mathematics learning}

As already noted, the large body of research accumulated since the middle of the twentieth century has brought much support for the claim that digital technologies, if appropriately applied, may bring improvements in learning outcomes. Moreover, findings suggest that with appropriately designed tasks, digital means turn out to be particularly helpful to students with a history of low achievement in mathematics or "with special educational needs" (e.g., Baccaglini-Frank \& Di Martino, 2019; Hourcade, Bullock-Rest, \& Hansen, 2012; Leung \& Baccaglini-Frank, 2017; Robotti \& Baccaglini-Frank, 2017). Either explicitly or implicitly, and from different theoretical perspectives, these findings imply that such a support can lead students to make sense of the mathematics they are learning (Healy \& Sinclair, 2007; Palmas, Rojano, \& Sutherland, 2020; Sinclair, Healy, \& Reis Sales, 2009). More specifically, in the context of inclusive mathematics education at the high school level, many qualitative studies have focused on the means offered by technology to support students' discovery through visualization and manipulation (of representations) of mathematical objects (e.g., Hollebrands \& Okumus, 2018; Robotti, 2017; Robotti \& Baccaglini-Frank, 2017). Such learning processes can involve mathematical generalization through the manipulation of digital artifacts (e.g., Antonini, BaccagliniFrank, \& Lisarelli, 2020; Santi \& Baccaglini-Frank, 2015), and they can be enhanced by collaboration among peers (e.g., Hegedus \& Tall, 2016).

Research has also shed light onto the question of the mechanisms through which digital mediation impacts the process of learning. Studies on the role of technology in high school, especially those using the theoretical lens of the approach known as "instrumental," have 
studied relationships between a student, a task, and a technological tool, showing how the student both continuously "shapes" the tool and "is shaped" (cognitively) by the tool throughout the learning process (e.g., Artigue, 2002; Arzarello, Olivero, Paola, \& Robutti, 2002; Baccaglini-Frank \& Mariotti, 2010; Baccaglini-Frank, 2019; Geraniou \& Jankvist, 2019; Leung, Baccaglini-Frank, \& Mariotti, 2013).

The study to be presented in this paper is meant to add to this literature by addressing the issue of how a technological environment may not just shape students' mathematical learning but also possibly enable it in the first place. Adopting a theoretical approach that can be described as "discursive," the study will show in detail how such shaping and enabling can take place, and it will do this by providing a detailed qualitative account of events in which a digital environment allowed low-achieving students to construct the abstract objects that they needed in order to be able to develop meaningful mathematical narratives. My first task, however, is to introduce the discursive framework.

\section{Mathematics as discourse and mathematical objects as discursive constructs}

The diversity of theoretical perspectives that have been used to study how dynamic geometry and algebra environments at the high school level contribute to students' mathematical learning makes it difficult to draw comparisons or build new research on the results reported in the literature. This is particularly true for findings from research conducted in the context of low achievement in mathematics. Recently, a few studies focusing on students' learning within technological environments have started adopting Sfard's (2008) discursive approach (e.g., Lisarelli, 2019; Antonini et al., 2020; Ng, 2016; Sinclair \& Heyd-Metzuyanim, 2014) that I introduce in the next section. These studies have started to unveil discourse that develops within such environments, especially in the mathematical context of functions. However, much research is yet needed to further grasp the discursive roles played by technology in students' learning, especially when the students have a history of low achievement or failure in mathematics (Baccaglini-Frank \& Di Martino, 2019, in press). Filling this gap could lead to better knowledge of mechanisms of students' failure in mathematics and provide insight into how to help more students overcome it or avoid it all together.

The discursive approach is also known as commognitive (Sfard, 2008, 2018)-a word composed of communication and cognition, which signals the ontological unity of communicating and thinking. Doing mathematics means engaging in a particular type of communication characterized by specific words (e.g., four, square, function, parabola), visual mediators (e.g., $5 x+3$, a graph of a function), endorsed narratives (e.g., theorems, definitions and computational rules), and routines (patterned ways in which its characteristic tasks are performed) (Sfard, 2008, 2018). Learning mathematics is the activity of developing this special discourse.

The discursive approach is particularly appropriate for this study because it bridges individual and societal learning conceptually, escaping the pitfall of the talk of deficit (Heyd-Metzuyanim, 2013; Heyd-Metzuyanim, Tabach, \& Nachlieli, 2016; Lewis, 2017; Sfard, 2008), and reconceptualizing the situativity of learning (Lavie, Steiner, \& Sfard, 2019). In the paragraphs below, I focus on specific aspects of this theory that are key to our study. 
This study builds on research that has used the discursive approach to study digital visual mediators - or DIMs, for short - in students' discourse on functions. $\mathrm{Ng}$ (2016) has introduced a distinction between static and dynamic mediators, which Lisarelli, Antonini and BaccagliniFrank (Antonini et al., 2020; Lisarelli, 2019) have further elaborated, reaching the notion of dynamic interactive mediators (DIMs), digital objects constructed within technological environments that can be manipulated and that give immediate feedback based on such manipulations, in the form of dynamic change; and that for experts in mathematics are realizations of mathematical objects (or aspects of them). Antonini et al. (2020) have suggested that DIMs can enable forms of discourse about functions that are not yet formal but that contain meaningful narratives that an expert can "translate" into canonical mathematical discourse. I will write more about this in Section 3.3.

\subsection{Concrete and abstract mathematical objects}

The distinction between concrete and abstract objects (Sfard, 2008, 2018) is central in this study. An algebraic expression can be seen by students as either a concrete object - the string of symbols on paper or on computer screen - or as a signifier of an abstract object. This distinction is similar to the one between a name of a person (which can be treated as a concrete object, visible when written and audible when pronounced) and the person whose name that is (although she is not an abstract object). So an algebraic expression can be a concrete object, an unrealized mathematical signifier, or a signifier for a mathematical object, in this case either a number or a function. Following Sfard (2008), one can say that a student views, say, $x^{2}-5 x+21$, as (a signifier of) an abstract object (number or function) when for this student, the expression has many realizations, that is, can be "written in different ways." In other words, the student is aware of the existence of other expressions that in certain contexts can count as equivalent to this one. As long as an expression has no realizations, this expression is just a concrete object that stands for nothing but itself and can only be manipulated in well-defined ways. Viewing an expression as an unrealized symbol may be compared with knowing a name of a person without ever meeting the person herself or having much information about her.

When the student begins to speak in terms of abstract objects and their properties (as opposed to speaking in terms of unrealized symbols and operations on these symbols), her discourse has become objectified.

\subsection{Explorative versus ritualistic participation in mathematical discourse}

Participation in mathematical discourse may take different forms, depending on how students engage in discursive routines. According to Lavie et al. (2019), this last term refers to "repetition-generated patterns of our actions" (p. 101). More precisely, a routine is the pair composed of a task and a procedure (Sfard, 2018). A task, as understood by a person in a given task situation (any setting in which a person considers herself bound to do something), is the set of all the characteristics of the precedent events (all that happened in a precedent task situation) that she considers as requiring replication. A procedure implemented by the task performer in response to a given task situation is the prescription for action that fits both the present performance and those on which it was been modeled.

If participation takes the form of just an implementation of memorized routines for the sake of themselves, with the performer never attending to any product of this performance that could later be used independently of the procedure that produced it, it is called ritualistic or 
simply ritual (Sfard, 2017). In this case, students act mainly with concrete objects (e.g., unrealized algebraic expressions), and they do not have an intention to tell a story about a mathematical object. Their interest is exclusively in the very performance of the procedure, which is seen as a mere symbolic manipulation. In ritualistic participation, no new decisions are made and students resort to recalling and imitating procedures as presented in textbooks or by the teacher.

On the other hand, participation can be explorative, aimed at constructing a meaningful narrative about abstract objects (e.g., numbers, functions). Students who participate exploratively act as problem solvers and engage in this kind of talk for themselves, in order to make sense of a particular task situation. In terms of agency, if students participate exploratively, they tend to propose new actions or outcomes. So, while ritualistic discourse is expressed in terms of processes and students' actions in and of themselves, explorative discourse is centered around mathematical objects. It is important to note that explorative and ritualistic discourse are at the extremes of a continuum of possibilities, and a particular student's discourse is almost never at one of the extremes.

\subsection{A conjecture about how DIMs can contribute to objectification of mathematical discourse and this study's research question}

According to the basic theoretical assumption in which this study is grounded, people are interpreters, or sense-making creatures. The need for a consistent interpretation of what is going on underlies their actions wherever they go. In the absence of such interpretation, they are lost. The fact that we often may be caught acting inconsistently does not contradict this last statement. Lack of consistency may stem merely from our being insufficiently alert to possible contradictions. Accordingly, to make-sense of something is to construct a convincing story about this something. A meaningful story needs to be consistent, comprehensive and cohesive (Sfard, 2008, 2019).

Moreover, each story has protagonists: without them the story cannot be told. If you are unable to identify the object about which you are, and are nevertheless, required to answer (tell a story), you can only respond by going through the motions, that is, by acting ritualistically.

When dealing with mathematical task situations, you have an incomparably greater chance of success if you are able to view a signifier like $x^{2}-5 x+21$ as an abstract object, as opposed to just an unrealized signifier. To explain the advantage of approaching the expression as an abstract object, consider this metaphor. Imagine two situations: (1) you know only a name of a person, N, because it was mentioned in your presence a number of times, or (2) you know the person herself. Now, imagine that you are asked questions about N. For instance, you are asked whether you think that a certain dress would fit her. Can you answer this question if (1) is the case? How much can you tell if you only know her name and have heard just one or two brief stories about her? If in the past her name was mentioned in your presence and something was said about her body size, you may still be able to answer, even if rather hesitantly. But if you do know the person - if you actually met her in the past - your ability to answer will be incomparably greater. This is the case, because you can recall how she looks and because you are able to deduce her size from a memorized image of her standing next to things or people, comparing it with sizes with which you are familiar. And there is more. If you know a person (the object signified by N), you can figure out things about her of which you were not aware before.

The visual realization of an abstract object, which is usually one of many, is nevertheless of particular importance: through it one can derive properties of the object by just scanning its image in certain ways. The most important advantages of visual realizations, such as a graph of function, 
reside in their power to connect to other realizations, like an algebraic expression, a table, a verbal description, etc. Moreover, if one can interact with such visual realizations (in digital environments such as GeoGebra), the potential to connect to other realizations increases.

Realizations, like graphs and draggable points and lines, can become dynamic interactive mediators (DIMs) (Antonini et al., 2020), programmed by experts by design to react to inputs in ways that are consistent with those expected of a realization of a certain mathematical object. Moreover, there is a well-defined repertoire of admissible actions that an individual can carry out. So, a solver can entertain discourse with DIMs, interacting with them as if they were "peers" (e.g., a student can ask the DIM to show her solutions to an equation), or she can talk about them in her stories (e.g., a student can drag a horizontal line across a graph on the screen and use it to describe the set of images of the function realized by the graph). When a solver's discourse is about DIMs, these may be treated either as concrete interactive objects (e.g., a student points to intersections between lines in response to a question or she drags a constructed object on the screen to show a particular behavior of the DIMs) or as realizations of abstract mathematical objects (e.g., a student refers to intersections between a graph of $f$ and the $x$-axis as solutions to the equation $f(x)=0$ ). This last case is typical of experts.

Antonini et al. (2020) present examples of students' written discourse about DIMs that for experts are realizations of functions, showing how such discourse can be "translated" into experts' discourse. For example, students write: "B's position is static while a $[\mathrm{A}]$ can move around" (Antonini et al., p. 17), to indicate what an expert might express as: " $f$ is a constant function." This example also shows how the same DIM can be treated as a concrete object or as a realization of an abstract object.

What is interesting here is how actively the students engage in the activities with DIMs, constructing meaningful narratives about them. Indeed, Antonini et al.'s study echoes an earlier study by Sinclair et al. (2009) presenting students' narratives about a variety of DIMs, again realizations of functions. The study highlights the potential of the DIMs' interactiveness and dynamism for students' sense-making and engagement.

So, from an educational point of view, although the learning path may still be long, discourse about DIMs may constitute a step towards mathematical discourse and, in this sense, a form of participation in such a discourse. Moreover, studies suggest, although mostly implicitly, that in an environment like GeoGebra, students' participation tends to be explorative and that students are less intimidated than when mathematical discourse is initiated in other contexts. However, to my knowledge, no studies have yet unraveled in fine-grained detail, from a commognitive perspective, how DIMs can foster explorative participation in mathematical discourse.

I conjecture that a key to studying this relies on the fact that DIMs support the construction of abstract objects. Once the student's discourse is objectified, she is more likely to tell fullfledged mathematical stories and, thus, to engage in explorative participation. My examination of this conjecture will be guided by the following general research question:

GRQ: Can DIMs in a digital environment support students' explorative participation in mathematical discourse and if so, how do they do this?

\section{Methodology}

The data were collected in a larger study on the impact of using dynamic geometry and algebra software extensively with high school students presenting a history of low achievement and 
low motivation in mathematics. There are several reasons why "function" was chosen as the focal mathematical object. Discourse on functions plays a leading role in mathematical theory, in mathematical practice, and in school. In addition, considerable difficulties experienced by learners in this domain have long drawn researchers' attention as a resource of insights about mathematics learning (e.g., Carlson \& Oehrtman, 2005; Goldenberg, Lewis, \& O’Keefe, 1992; Nachlieli \& Tabach, 2012).

\subsection{Design of the study}

Here I present a case study involving dyads of students from two classrooms, in their third year (age 16-17) at a vocational high school for "economics and commerce." One classroom - the "DIM class" - had been selected for the study because its teacher (a participant of my research group and former student of my math education course) had lamented it being "highly demotivated and quite low-achieving" after its first year. Under my guidance and inspired by activities on functions for high school students available in an Italian textbook (BaccagliniFrank \& Poli, 2015), the teacher had decided to implement a new teaching sequence: he started using activities with DIMs to introduce linear and quadratic relationships, as well as other functions, exploring them through the manipulation of graphs in GeoGebra. Such manipulations included constructing points to drag along the $x$-axis, the $y$-axis, or the graph itself and intersections between the graph and lines perpendicular to one of the axes. During these manipulations, students learned to attend to variations both in the graphical layout and in the algebraic window of GeoGebra. Students from this classroom were used to having access to GeoGebra at all times. Over the year prior to the interviews, I had watched videos from the DIM class and corresponded with its teacher but never met any of the students in person.

For the specific study presented here, as a contrasting background on which the potentially special features of the DIM class might stand out in stronger relief, I also interviewed students from a "background class." The teacher from this class had taught the same content but without using DIMs regularly; in fact, he had taken his students to the computer lab only twice during the previous year. So, students from the background class were not accustomed to using technological environments. The students selected by their teacher for the interviews were presented to me as average-to-high achievers with no history of mathematical learning difficulties.

\subsection{Data collection}

The interviews took place in the first half of the school year. Three dyads of students were interviewed from each class. The interview questions (see SM2) were designed to be about functions (though the word "function" was not used until the last interview questions), and they were designed to promote students' discourse about functions. The questions were also designed to involve mathematical content covered by both classes, but they were posed in potentially unfamiliar forms. That is, the questions were not posed in the typical ways in which textbooks would present them. The interviews were conducted in Italian; here I translated all transcripts into English.

I was the interviewer; none of the students had previously met me. While I had seen videos of activities with the students of the DIM class, I had no previous information about the students from the background classroom. I offered all students a computer with GeoGebra if they wanted to use it at any point during their interview. Each interview lasted between 60 and $75 \mathrm{~min}$. Data were collected in the form of video recordings (from behind the students' backs 
to capture their writing and gestures), verbatim transcriptions, students' written productions, and screen recordings (if the students chose to use GeoGebra).

I focus here on excerpts from the interviews of two dyads that I refer to as "the background dyad," composed of two girls, Emi and Mar, and "the focal dyad," composed of a boy and a girl, Gal and Sun. I chose the focal dyad because Gal had been particularly demotivated and low-achieving during his first year of high school, according to his teacher. I interviewed him together with his slightly more diligent classmate Sun, with whom he was used to conversing in the classroom. I was particularly interested in the case of Gal because from "not participating whatsoever in mathematics," as stated by his teacher at the end of his first year of high school, when GeoGebra was introduced during his second year, he "lit up", and came to be one of the students who showed the greatest difference in his patterns of participation.

I chose the background dyad because its answers were comparable to those of the other dyads of the background class and it engaged in the interview questions for similar amounts of time as the focal dyad.

For this case study, I selected excerpts from the interview question "A classmate of yours, Nicola, claims that $x^{2}-5 x+21$ is never greater than $5 x+3$. Is this true or false?," because of the similar structure of the two dyad's answers. The complete list of interview questions is included in the Supplementary Materials SM2.

\subsection{The analytic scheme}

To contribute to an answer to the general research question (see the GRQ at the end of section 3.3), I planned to answer the following specific guiding questions:

SRQ1. To what extent was the discourse of each dyad more ritualistic or more explorative?

SRQ2. What were the main differences of the focal dyad's discourse with respect to that of the background dyad and how can these be related to these students' interactions with DIMs?

In order to answer SRQ1, I analyzed each dyad's transcript, highlighting features indicative of either ritualistic or explorative nature of their discourse. To do this, I focused on the following four features introduced in the theoretical framework:

1. The degree of objectification, that is, the nature of the objects in the discourse-whether they were abstract or just unrealized symbols

2. The task as it is understood by the students - whether the students were process or product oriented

3. The degree of students' agency, that is, the relative amount of independent decisions made by each dyad

4. The dyad's capability for sense-making, expressing itself in the students' ability to tell stories about mathematical objects

These four properties are further operationalized in Table 1 through types of communicational indicators to be identified in the text of the transcripts. These indicators are designed to shed light on the nature of each dyad's participation and its engagement with DIMs, when it occurs. In the fourth column of Table 1, I give some examples of indicators suggesting more explorative or ritualistic participation, noting, however, that any specific interpretation needs 
Table 1 Analytic scheme used for analysis of the data

\section{Aspects of the Questions guiding the analysis Communicational indicators Examples} discourse

\begin{tabular}{|c|c|c|c|}
\hline $\begin{array}{l}\text { 1. Objects in } \\
\text { focus }\end{array}$ & $\begin{array}{l}\text { What is the conversation about } \\
\text { objects and their properties } \\
\text { or unrealized symbols and } \\
\text { one's actions with these } \\
\text { symbols? } \\
\text { - How many realizations of the } \\
\text { same signifier are used? } \\
\text { How are the transitions } \\
\text { between realizations made? } \\
\text { - Are DIMs used as objects in } \\
\text { the discourse? How? }\end{array}$ & $\begin{array}{l}\text { (a) Terms or visual mediators } \\
\text { used as precedents } \\
\text { identifiers } \\
\text { (b) Signifiers mentioned: in } \\
\text { relation explicitly to the } \\
\text { outcome of the routine, or } \\
\text { only in relation to } \\
\text { memorized steps of a } \\
\text { procedure (perhaps } \\
\text { implicitly) } \\
\text { (c) Additional realizations } \\
\text { mentioned } \\
\text { d) presence of transitions } \\
\text { between realizations } \\
\text { (e) DIM is unrealized symbol } \\
\text { (f) DIM is realization of } \\
\text { mathematical object }\end{array}$ & $\begin{array}{l}\text { Explorative: "this function", } \\
\text { " } x^{2}+5 x-3 \text { is a parabola" } \\
\text { "if } x \text { is } 1, \text { I get } 9 \text {, so } f(1)=9 ", \\
\text { "the solutions of } \\
x^{2}+5 x-3=0 \text { are where } \\
\text { parabola intersects the } \\
x \text {-axis" } \\
\text { Ritualistic: "it", "them" to } \\
\text { indicate signifiers, "you } \\
\text { have to draw a line" }\end{array}$ \\
\hline Task & $\begin{array}{l}\text { Is the task familiar (are the } \\
\text { students able to identify a } \\
\text { precedent)? Is this to } \\
\text { perform a procedure or to } \\
\text { produce an endorsed } \\
\text { narrative? }\end{array}$ & $\begin{array}{l}\text { (a) Restatement of the task } \\
\text { (b) Words or visual mediators } \\
\text { prescribing action in the } \\
\text { given task situation (in } \\
\text { relation to endorsed } \\
\text { narrative, or simply about } \\
\text { what needs to be done in the } \\
\text { procedure) } \\
\text { (c) Subtasks feeding into the } \\
\text { procedure }\end{array}$ & $\begin{array}{l}\text { Explorative: "This is like ..." } \\
\text { "So we can find where it is } \\
\text { positive" } \\
\text { Ritualistic: "First you do..., } \\
\text { then you do..." }\end{array}$ \\
\hline 3. Agency & $\begin{array}{l}\text { Are independent decisions } \\
\text { made? Which ones? }\end{array}$ & $\begin{array}{l}\text { (a) References to memory with } \\
\text { regard to procedure to be } \\
\text { carried out } \\
\text { (b) New proposal for how to } \\
\text { proceed } \\
\text { (c) Appropriateness of the } \\
\text { performance according to } \\
\text { the outcome is actively } \\
\text { monitored or not monitored }\end{array}$ & $\begin{array}{l}\text { Explorative: "I/we can type } \\
\text { in...", "let us try", "we } \\
\text { could", "this is right } \\
\text { because..." } \\
\text { Ritualistic: "you have to", "to } \\
\text { do the delta you..." }\end{array}$ \\
\hline $\begin{array}{l}4 . \\
\text { Sense-- } \\
\text { making }\end{array}$ & $\begin{array}{l}\text { Were there signs that the } \\
\text { participants were concerned } \\
\text { with the consistency, } \\
\text { comprehensiveness, and } \\
\text { cohesiveness of their } \\
\text { narratives? }\end{array}$ & $\begin{array}{l}\text { (a) Requests to the interviewer } \\
\text { for clarification } \\
\text { (b) Tone of voice and gestures } \\
\text { express: confidence or } \\
\text { bafflement/embarrassment } \\
\text { (c) Anything showing whether } \\
\text { students' discourse makes } \\
\text { sense mathematically (e.g., } \\
\text { linguistic connectors that } \\
\text { indicate an attempt to } \\
\text { connect utterances logically; } \\
\text { mathematical words used } \\
\text { appropriately) } \\
\text { (d) Students expect/do not ex- } \\
\text { pect outcome of procedure } \\
\text { or of interaction with DIM } \\
\text { (e) Students recognize outcome } \\
\text { of procedure as related/not } \\
\text { related to task }\end{array}$ & $\begin{array}{l}\text { Explorative: "I know", } \\
\text { confident smile, "this is } \\
\text { right because...", "I get it", } \\
\text { ", "if..., then...", "so we } \\
\text { have concluded", } \\
\text { Ritualistic: "uh...", "I do not } \\
\text { know", "I have no idea" }\end{array}$ \\
\hline
\end{tabular}


to be checked for consistency with the more global interpretation of the excerpt and, more generally, of the whole transcript. The analytical findings guided by the scheme in Table 1 will constitute my answer to SRQ1, to be given separately for each dyad. Only after SRQ1 is answered for both dyads, will I be able to respond to SRQ2.

\section{Data analysis}

"A classmate of yours, Nicola, claims that $x^{2}-5 x+21$ is never greater than $5 x+3$. Is this true or false?" was the question posed by the interviewer to both dyads. Each one made two attempts to answer, so I partitioned each transcript into the two corresponding portions, Attempt I and Attempt II. Interestingly, each attempt revealed the same two-step structure: (a) the students tried to interpret the task situation and identify the task, and (b) they tried to identify and implement a procedure. The Supplementary Materials (SM) include, in SM1, the division (Table SM1) as well as the more complete coded transcripts (Tables SM2-SM10). For the sake of brevity, in the body of the paper, I include transcripts only of the dyads' second attempts, but I include analyses of both attempts of each dyad.

\subsection{Answering SRQ1 for the background dyad}

\subsubsection{Attempt $\mathrm{I}^{1}$}

Objects There are multiple signs here showing that these are unrealized signifiers rather than abstract objects that the girls focus on all along. When seeing the expression $x^{2}-5 x+21$ written down by Mar ([3]), the girls evidently turn to previous classroom experiences involving quadratic expressions in the form $a x^{2}-b x+c$. They even seem to consider the second expression Mar wrote, $5 x+3$, as a special case of such a form: Emi exclaims "But $x^{2}$ is missing..." [51]. The signifiers are almost never mentioned explicitly, but only referred to through terms such as "it" ([5], [8], [19]), "them" [12], and "the first/s" ([14], [16]). The fact that these are not signifiers of mathematical objects but only of unrealized symbols is also evidenced by the verbs in their sentences, such as "solve it/them" ([8], [12]), "do the delta" [24], "you couldn't do it" [37], "you can't factor it?" and [42], "you cannot..." [43]. No transitions to other realizations are made. No DIMs are used as objects in the discourse.

Tasks The task situation appears to be unfamiliar to the students: they do not seem to immediately recall any precedent and they do not reformulate the request in any way. Referring to the two expressions, Mar says "solve them" [12]. The plural form indicates that each of the two expressions she has written is to be operated upon separately. Execution of such a memorized "solving" procedure on each expression, rather than any outcome of this action, seems to be what she identifies as her task. Stating "I mean factor to see..." [19] she declares that the procedure she chose is to factor the expressions. Moreover, they automatically apply the well-known formula for finding $x_{1}, x_{2}$ with the help of $\Delta$ and are stuck when the latter turns out negative. There is no mention of an expected or actual result of any of these actions. So there is an ample evidence that the dyad sees the performance of the procedure as its task.

\footnotetext{
${ }^{1}$ Transcript utterances refer to Table SM2 and Table SM3 in the Supplementary Material SM1 for the online version of this article
} 
Agency Since the students see it as their task to perform a memorized sequence of steps (e.g., "First this..and then this, you find" [8] and similar in [12], [24], [36], [37]), there is no space for their own decisions about how to proceed. Once they have decided what procedure to apply, they make no new proposals and do not monitor the appropriateness of performance according to the outcome.

Sense-making Since the students focus on a performance, not any new narrative, there is also not much room for sense-making. Indeed, there is no story telling activity here. For the students, the symbols do not stand for anything but themselves, and the procedure is something to do, not to make sense of. The students seem to be confused by the task situation and do not connect their utterances logically. Indeed, when the interviewer attempts to discuss the reasons for selecting and carrying out the specific procedures to shift the discourse away from the description of a procedure, the students express bafflement ("How could we do?" [47], "I don't know" [55], [62]).

\subsubsection{Attempt II}

The dyad's second attempt starts after the interviewer tries to restate the question, explicitly presenting an inequality (see Table 2 below and Table SM4).

Objects Once again the students' discourse is focused on unrealized symbols: they associate the new written inequality $x^{2}-5 x+21<5 x+3$ [66] to experiences involving quadratic inequalities where reducing to canonical form and finding its zeros were part of the formal symbol-manipulating procedures they applied. The signifiers are not mentioned explicitly but only referred to implicitly through terms such as "it" ([69], [75]) and "they" ([142], [145]). This is particularly evident when Emi and Mar imperfectly recall how in the end one chooses either the "internal" or the "external" [values of $x$ ]: the students do not even use a noun to express what these words supposedly describe [142]. The fact that these are not signifiers of

Table 2 Step Ila: Reinterpreting task situation - looking for precedent and deciding on the task

\begin{tabular}{|c|c|c|c|}
\hline N. & P. & What is said ${ }^{1}$ & What is done \\
\hline 65 & Int. & $\begin{array}{l}\text { If it had been written like that }\left[x^{2}-5 x+21>5 x+3\right] . \text { would } \\
\text { it have been the same question? Yes, no, why? }\end{array}$ & \\
\hline 66 & Mar & Greater than five $x$ plus three & Writing " $x^{2}-5 x+21>5 x+3$ " \\
\hline 67 & Int. & $\begin{array}{l}\text { Yes. Or, instead, well Nicola would have said the opposite, } \\
\text { he would have said less than, yes. }\end{array}$ & \\
\hline 68 & Emi & Less than, yes. & \\
\hline 69 & Mar & Is it less than? & Writes " $x^{2}-5 x+21<5 x+3$ " \\
\hline 70 & Int. & Turn the sign. Yes, yes, yes. Ok. & \\
\hline 71 & Int. & Is it the same thing? & \\
\hline 72 & Mar & No, I mean, like this maybe I would know how to do it.. & \\
\hline 73 & Int. & Maybe you would do something else. & \\
\hline 74 & Mar & Yes & \\
\hline 75 & Emi & You do it like.. & \\
\hline
\end{tabular}

Step IIb is presented in Table 3 (and in Table SM5)

${ }^{1}$ Please note that in the transcript students' shorter pauses are indicated with ".." and longer pauses with "..." 
Table 3 Step IIb: Identifying procedure that fits the task and implementing it

\begin{tabular}{|c|c|c|c|}
\hline N. & P. & What is said & What is done \\
\hline $\begin{array}{l}76 \\
\text { they }\end{array}$ & $\begin{array}{l}\text { Mar } \\
\text { carry out the }\end{array}$ & $\begin{array}{l}\text { I mean, here you take all the } \\
x(s) \text { over and it comes out.. } \\
\text { calculations] }\end{array}$ & $\begin{array}{l}\text { Points to the " } 5 x \text { " on the right-hand } \\
\text { side of the inequality }\end{array}$ \\
\hline 87 & Emi & Uhm..equal..uh, less than & \\
\hline $\begin{array}{l}88 \\
89\end{array}$ & Mar & $\begin{array}{l}\text { Less than zero. } \\
\text { PAUSE }(4 \mathrm{~s})\end{array}$ & Writes " $x^{2}-10 x+18<0$ " \\
\hline 90 & Mar & Here you do the delta anyway & \\
\hline 91 & Emi & Uhm & \\
\hline 92 & Int. & $\begin{array}{l}\text { So written like this you } r \\
\text { ecognize it, let us say, } \\
\text { as something more familiar. }\end{array}$ & \\
\hline $\begin{array}{l}93 \\
{[\ldots]}\end{array}$ & Emi \& Mar & Yes. & \\
\hline 100 & Mar & So delta.. & \\
\hline 101 & Emi & You do the delta & \\
\hline \multicolumn{4}{|c|}{ [They carry out the calculations and Mar writes $\Delta=100-72=28$.] } \\
\hline 117 & Emi & $\begin{array}{l}\text { And so then it comes out } \\
\text { to be twenty eight..the delta. }\end{array}$ & Mar writes " $\Delta=100-72=28 "$ \\
\hline \multicolumn{4}{|c|}{ 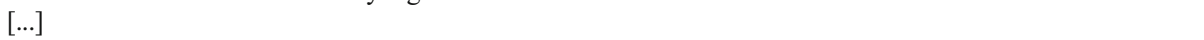 } \\
\hline 124 & Emi \& Mar & Plus or minus..square root of twenty eight & \\
\hline \multicolumn{4}{|c|}{ [Mar writes " $\left.x_{1,2}=10 \pm \sqrt{28} ".\right]$} \\
\hline 129 & Mar & Over & \\
\hline 130 & Emi & Two a, so 2 , yes & \\
\hline 131 & Mar & Two & Mar writes " $x_{1,2}=\frac{10 \pm \sqrt{2} 2}{2}$ " \\
\hline 132 & Mar & \\
\hline 133 & Int. & \multicolumn{2}{|c|}{ Ok, alright, two numbers, what are you going to do with these two numbers? } \\
\hline 134 & Emi & \multicolumn{2}{|c|}{ Eh.... } \\
\hline 135 & Int. & \multicolumn{2}{|l|}{ What do you need them for, uh.. } \\
\hline 136 & Emi & You [were supposed to] do this, no? I mean the... & $\begin{array}{l}\text { Gesture tracing a segment with her } \\
\text { finger to the right of the } x_{1}, x_{2} \text {. }\end{array}$ \\
\hline 137 & Mar & \multicolumn{2}{|l|}{ Ah, yes. } \\
\hline 138 & Mar & \multicolumn{2}{|l|}{ The thing with the two $x(s)$} \\
\hline 139 & & \multicolumn{2}{|l|}{ PAUSE $(5 \mathrm{~s})$} \\
\hline 140 & Mar & \multicolumn{2}{|l|}{ With, like.. I do not know.. } \\
\hline 141 & Mar & Here there is $x$ sub one and here $x$ sub two & Draws a line with two ticks for $x_{1}$ and $x_{2}$. \\
\hline 142 & Mar & Then, since it's less than, they are internal? & Draws two circles above the ticks and \\
\hline 143 & Mar & & connects them (Fig. 1) \\
\hline 144 & Mar & Right? & Embarrassed smile \\
\hline 145 & Mar & \multicolumn{2}{|c|}{ Because if it had been greater than they would have been external, for external values. } \\
\hline 146 & Emi & \multicolumn{2}{|l|}{ Uhm } \\
\hline 147 & Mar & \multicolumn{2}{|l|}{ Less than for internal values of $x$. } \\
\hline 148 & Int. & \multicolumn{2}{|c|}{$\begin{array}{l}\text { Ok. So with that little line there that you drew [referring to segment } \\
\left.\text { drawn between } x_{1} \text { and } x_{2}\right] \text {..what...what can you say? }\end{array}$} \\
\hline 149 & Int. & \multicolumn{2}{|c|}{$\begin{array}{l}\text { What does it have to do with Nicola's initial claim, or at least, let us say, } \\
\text { with the second writing..with the less than? }\end{array}$} \\
\hline 150 & & \multicolumn{2}{|l|}{ PAUSE (16 s) } \\
\hline 151 & Mar & & Shakes her head helplessly \\
\hline 152 & Int. & \multicolumn{2}{|l|}{ It's hard. Ok, it's alright. } \\
\hline 153 & Mar & No, I do not know. & Embarrassed smile \\
\hline 154 & Emi & I would not know. & Embarrassed smile \\
\hline
\end{tabular}

mathematical objects is further evidenced by the verbs: "you take all the $x(s)$ over and it comes out.." [76], "you do the delta" [90], [101] (and similar expressions in [117-132]). The students make only one transition to a different realization of solution of an inequality, the "thing with 


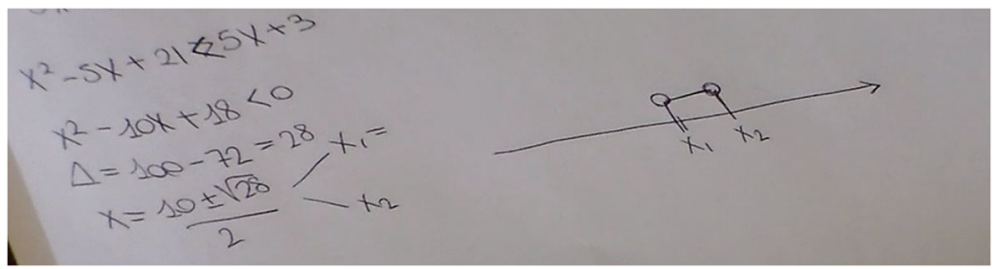

Fig. 1 Mar draws a picture for "internal [values]" between $x_{1}$ and $x_{2}$

the two $x(s)$ " [138]; however, for them, this too is only part of a memorized procedure they are trying to recall. No DIMs are used.

Tasks Faced with the new inequality suggested by the interviewer, the students seem to recognize a different task; the unfamiliarity of the first request is in contrast with the apparent familiarity of the modified request that they "maybe would know how to do" [72]. The students never state a general task explicitly, but I infer it to be something like: "do what we did in the class when faced with an expression $a x^{2}+b x+c<0$." The many utterances about what needs to be done, such as "take all the $x(s)$ over and it comes out" [76], "do the delta" ([90], [101]), find " $x_{1,2}$ " [119-132], and do "the thing with the two $x(s)$ " [138], suggest that the students understand the task as a request perform a procedure in and of itself.

Agency Since the students are not attempting to construct an endorsed narrative, but only perform procedures they were both exposed to in class or in a textbook (e.g., "you do" or "do this" stated in utterances: [75], [90], [101], [118], [136]), they never make independent proposals about how to proceed. This is the case even when in the end they seem to realize that the outcome of their procedures is not related to the interviewer's question, as they state: "I don't know" [153], "I wouldn't know" [154]. This interpretation is strengthened by the fact that the students continue not to monitor the appropriateness of their performance according to the outcome (e.g., "Eh..." [134], “Right?" [144]), even when prompted by the interviewer (in [133], [148], [149]).

Sense-making Since once again the students see their task as a request to perform a symbolic procedure that they attempt to recall, as shown above, there is not much space for sense-making. Although Emi and Mar are relatively successful in applying the procedure to solve quadratic equations, they do not seem to recognize the outcome ("internal values of $x$ " [147]) as related to the interview question. Indeed, no indicators suggest that the students are concerned with consistency or cohesiveness of their narrative, and they acknowledge its lack of comprehensiveness concluding with helpless statements of surrender ("No, I don't know" [153], "I wouldn't know" [154]) when the interviewer tries to discuss the reasons for selecting and carrying out the specific procedures.

\subsubsection{Answer to SRQ1}

The analyses reveal that the background dyad talks about concrete unrealized algebraic symbols (first expressions and then the inequality), aiming at performing memorized procedures on them (to "solve it"/"factor it"/"solve them") for the sake of pleasing the interviewer, and with no apparent concern of constructing a consistent, comprehensive, or cohesive narrative. The characteristics of the dyad's discourse situate it more towards the ritualistic end of the spectrum. 


\subsection{Answering SRQ1 for the focal dyad}

\subsubsection{Attempt $\mathrm{I}^{2}$}

Objects Once Sun has transcribed into symbols the words she recognizes in the interview question, adding "is never" above the symbol " $>$ "[14], the objects in focus are the written inequality $x^{2}-5 x+21>5 x+3$, as well as two expressions on each side of the inequality symbol. These seem to lead the students to previous experiences, where they had probably compared algebraic expressions, finding outputs of each one by assigning input values to the " $x$ ", treating functions as input/output machines. The protagonists of Gal and Sun's discourse here are " $x^{2}$," "a number squared" [the number], and "five $x$ plus three" [24], which are treated as abstract objects with specific properties (e.g., " $x$ squared has to be..necessarily ..greater than" [24]). The students make a transition to a different realization when they choose to treat the algebraic expressions as numbers (e.g., "you give a value..any value to the $x$,..squared and then you take away this quantity" [30]). The dyad clearly attempts to tell a story about these abstract objects. No DIMs are used, although Gal suggests it (“eh, maybe drawing...” [20]).

Tasks The students seem to be trying to compare the left and right terms of the inequality, as if they were numbers (see [24], [30] quoted above). The students do not try to recall a memorized procedure, but they attempt to produce a narrative ("So in any case you take away a quantity that is greater than this" [30]).

Agency Gal makes independent proposals about how to proceed, first suggesting to draw in GeoGebra ([20] quoted above) and then attempting to produce a narrative about numbers ([30] quoted above). Moreover, the students' agency appears in their attempt to actively monitor the appropriateness of the outcome in relation to the interview question ("Maybe this is why he says that it is never greater" [37], "So it is less than" [38]).

Sense-making From the very start, this dyad seems to be concerned with making sense of the interviewer's question: Gal makes requests for clarification of the task (e.g., "less than in what sense?" [18]) and attempts to restate it ("that a number squared...x squared has to be..necessarily ..greater than...than five $x$ plus three" [24]). However, for the students, the narrative constructed until now still lacks comprehensiveness: in response to the interviewer's final question "do you think he is right or wrong?" [39], they propose a new line of action (in Attempt II).

\subsubsection{Attempt II}

The students construct a different narrative, this time using GeoGebra. Step IIb is presented in Table 4 (and Table SM9) for Sun, and in Table 5 (and Table SM10) for Gal, and it is carried out completely within GeoGebra.

Soon after, Gal chimes in, applying Sun's procedure to the line. Below is the transcript with his instantiation of Step IIb.

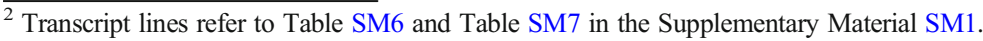


Table 4 Step IIb: Identifying procedure that fits the task and implementing it (for Sun)

N. P. What is said What is done

\begin{tabular}{lll}
\hline 48 & Gal & \\
49 & Sun & greater \\
50 & Gal & \\
51 & Sun & Five $x$ plus three... \\
52 & Gal & Should I write it all? \\
53 & Sun & Yes. \\
54 & Sun & Maybe you should put a parenthesis? \\
55 & Gal & Boh [expression of uncertainty] \\
56 & Sun & boh \\
57 & Gal & [inaudible] \\
58 & Sun No, I don't think so. \\
59 & Sun & eh \\
60 & Gal & Sorry \\
61 & Sun & enter...enter \\
62 & Gal Excuse me, what if we do them separate? \\
63 & Gal We could do a [It.: "una"] function \\
64 & Sun No, leave this here [S points to the left of the \\
& & screen where the inequality is] and then \\
65 & Gal Let's try, ...let's do one function
\end{tabular}
He writes the expression " $x^{2}-5 x+21$ " in the input bar in GeoGebra and stops

Continues typing in " $>$ "

He writes the whole inequality and hits "enter".

looking at screen shown in Panel 1

looking at screen shown in Panel 1

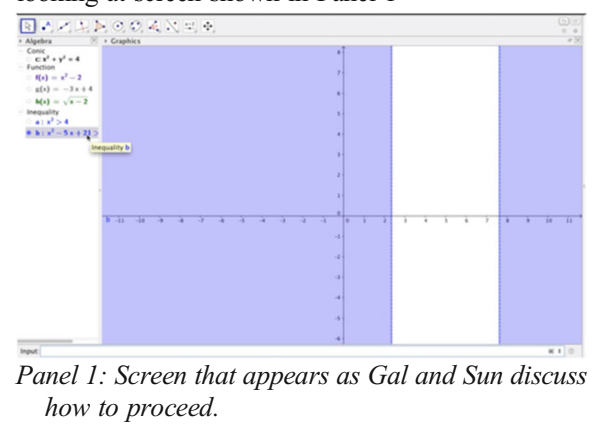

[Gal types in " $x^{2}-5 x+21$ " then " $5 x+3$ ", drags the screen and zooms in as shown in Panel 2]

79 Gal Ok. ... So...he said that it was less than...so

$80 \mathrm{Gal}$ It is always less than five $x$ plus three

81 Int. Yes.

82 Gal So five $x$ plus three ...would be a line.

83 Sun Yes.

84 Int. So show me what you are looking at there.

85 Gal Here?

86 Int. Yes.

87 Gal So, here...

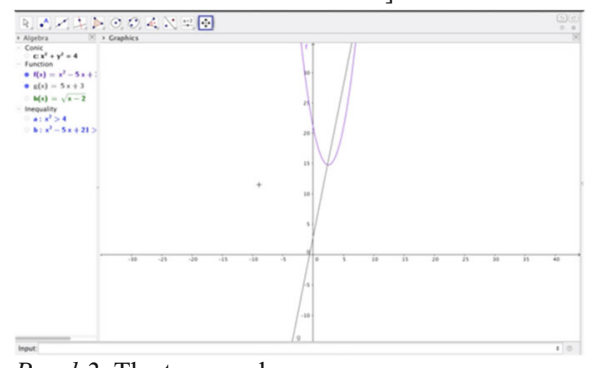

Panel 2: The two graphs on screen

88 Gal So...I think he maybe thought, that is if he gives a value to the $x$...... in this function [parabola], he obtains a corresponding $y$ always..always..

89 Sun Less than

90 Gal Less than

91 Int. Uhm

92 Gal than this

93 Int. And is it true?

[this $\rightarrow 5 x+3$ ]

94 Sun No.

95 Gal No?

96 Sun No

97 Sun No, because see these here, this one

She giggles

98 Gal Eh

99 Sun It doesn't always have the y less than the straight line.

[this one $\rightarrow$ graph of parabola]

["it" $\rightarrow$ graph of parabola]

Objects The main object of the students' discourse now is "function" (e.g., [63], [64], [88]) and the ways in which they talk about it suggest previous classroom activities in GeoGebra that involved creating a graph, describing its characteristics, giving $x$-values from the domain 
Table 5 Step IIb: Identifying procedure that fits the task and implementing it (for Gal)
N. P. What is said
What is done

108 Gal Yes, no, if I give ...now let's calculate only the line [Panel 3].

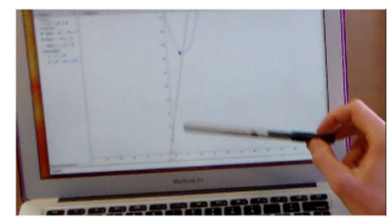

Panel 3: Gal "calculates the line"

109 Gal If I give the value two..to the line..I get...... [ Panel 4]

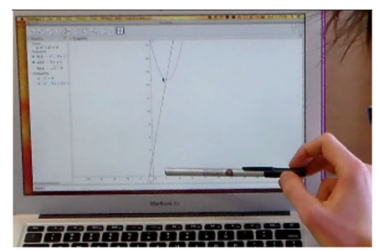

110 Sun

111 Gal

112 Gal More or less..let's say..fifteen [Panel 5]

113 Sun Excuse me, put the grid!

114 Gal Right.

$115 \mathrm{Gal}$

$116 \mathrm{Gal} \mathrm{OK}$

$117 \mathrm{Gal}$ uh...if I give it two..I get thirteen...for the line. [Panel 6]

118 Sun Instead for the parabola.. [Panel 7]

119 Gal If instead I give two to the parabola..

120 Sun There is fifteen. [Panel 8]

121 Gal I get..fifteen.
Panel 4: Gal uses his pen to make a vertical gesture giggles

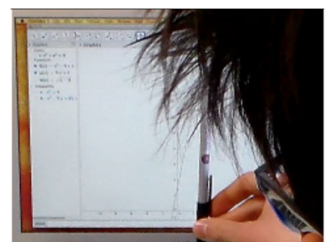

Panel 5: Gal uses a gesture to read the value of the line at 2 Giggles as he adds the grid

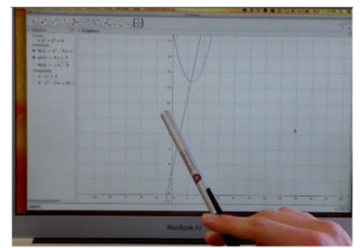

Panel 6: graphs on the screen as Gal points to the y-coordinates

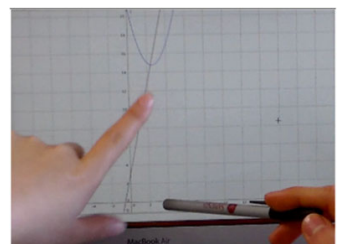

Panel 7: Sun (on the left) works with Gal (on the right) to "calculate the parabola"

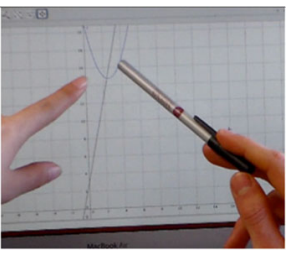

Panel 8: both students point to the $y$-value 15 of the parabola triumphant tone of voice 
and finding the corresponding $y$-values. The students refer to the signifiers using nouns related to the outcome of their routines: "two separate functions" [64], "one function" [65], a "line" ([82], [99], [108], [109], [117]), "this function" [88], a "parabola" ([103], [118], [119]), numerical values ("fifteen" [112], [120], "thirteen" [117]). These indicators suggest that the students' discourse is about the mathematical object function and its properties. Once they decide to "do a function" ([63]), the students' discourse shifts towards new realizations, graphs, specifically a "line" [108] and a "parabola" [118].

The students use DIMs extensively. Initially, the discourse is with the DIM "graphics window" in GeoGebra: the DIM responds to Gal's typing in the whole inequality [52-57], as if he were asking for an answer to the interviewer's question. Here the DIM is neither an unrealized symbol nor a concrete object, but a sort of participant in the discourse. Baffled by GeoGebra's strange feedback (Panel 1 in Table 4), the students reconduct the interaction to the generation of familiar graphs (from [79] on), new DIMs that they were clearly used to interacting with and talking about. These DIMs have discursive characteristics similar to those of abstract objects about which the dyad tells its story that involves transitions between the realizations: "write two separate functions" to produce graphs in GeoGebra [64]; "It doesn't always have the $y$ less than the straight line" [99], or "If I give the value two..to the line..I get......" [109], putting in relation numerical values and graphs.

Tasks Once the dyad proposes to "do them separate" [62], that is "write two separate functions" [64] and work in GeoGebra, Gal seems to reinterpret the interview question as "if he [the imaginary classmate Nicola] gives a value to the $x$...... in this function [parabola], he obtains a corresponding y" [88] and he types in the two functions ([66-68]), then adjusts the screen with confidence (Panel 2 in Table 4), suggesting that he is now in a more familiar situation. The dyad's attempts at reinterpreting the interview question until they are comfortable suggest that they see the task as the need to produce an endorsed narrative.

Agency The students make various independent decisions in their proposals about how to proceed (e.g., "Should I write it all?" [52], "What if we do" [62], "We could do" [63], "Let us" [65]). Moreover, they show agency in actively monitoring the appropriateness of their performance according to the outcome (e.g., "No, because see these here, this one" [97]): they even bond (Lavie et al., 2019) the outcomes of the procedures of "calculating" each function (using the DIMs generated [108], [119]), feeding each one into the overall task of comparing two functions by establishing $x$-values for which the $y$-values of the parabola are greater than those of the line ("And it's already greater" [122]).

Sense-making At first, the dyad is baffled by GeoGebra's strange feedback (Panel 1 in Table 4) ("boh [Italian exclamation of uncertainty]" [56], "No, I don't think so" [58]), but then it reconducts the interaction to the generation of familiar graphs (from [79] on). From then on the students act confidently (e.g., gestures [97-99], "And it's already greater" [122], satisfied grin [121-122]), they expect the outcome of the procedures carried out with DIMs (e.g., "It doesn't always have the $y$ less than the straight line" [99], "I get thirteen" [117], "There is fifteen" [120]). Moreover, they seem to be concerned with the cohesiveness and consistency of their discourse (e.g., use of "if...,[then]..." in utterance [88]; "because see" [97]). The students' narrative is also comprehensive: they answer "No, because see these here, this one" [97] "It [the parabola] doesn't always have the $y$ less than the straight line" [99] and proceed to show through an example (which is a counterexample to Nicola's claim in the 
interview question) that this is indeed the case ("[for $x=2]$ it's [the parabola is] already greater" [122]). The high level of sense-making in their discourse can also be seen in Gal and Sun's coordination: Gal gestures the vertical line through two with the movement of the tip of a pen, while Sun points to the corresponding $y$-value (Panels 7 and 8 in Table 5).

\subsubsection{Answer to SRQ1}

The findings reveal that Gal and Sun seem to be talking about properties of abstract objects (first numbers and then functions) manipulating DIMs that realize such mathematical objects and swiftly making transitions between them. Their discourse is overall aimed at constructing a meaningful response to the interviewer's question in the form " $x^{2}-5 x+21$ is/is never greater than $5 x+3$," and they construct their narrative through many new proposals for how to proceed, actively monitoring the appropriateness of each outcome. The identified characteristics of their discourse situate it more towards the explorative end of the spectrum.

\subsection{Answering SRQ2}

In SRQ2 I asked about the main differences of the focal dyad's discourse with respect to that of the background dyad and how such differences can be related to these students' interactions with DIMs. While the background dyad's discourse was about unrealized algebraic symbols, manipulated for the sake of pleasing the interviewer, the focal dyad's discourse was mostly concerned with constructing a consistent, comprehensive, and cohesive narrative about functions, as abstract mathematical objects. While the background dyad spoke about steps that "had to be done," recalling them from memorized procedures, the focal dyad suggested new ways of proceeding that involved new realizations. These realizations appeared in the form of DIMs generated with the software, and they acted as protagonists, guiding the students' construction of a meaningful narrative in response to the interview task.

The findings suggest that an important contribution of the DIMs resides in the ways in which students could interact with them and manipulate them even before becoming fluent in canonical mathematical discourse. Indeed, looking at differences in the ways in which the dyads manipulated their objects of discourse, the background dyad attempted to reproduce bits of canonical mathematical discourse but ended up mechanically manipulating algebraic symbols without making sense of them, while the focal dyad manipulated DIMs in non-canonical but meaningful ways. Indeed, the focal dyad's discourse was not expressed in canonical mathematical form, but the students seemed to have become so well-acquainted with manipulating DIMs through dragging actions in GeoGebra, that in the interview they mostly used gestures (Panels 5-8 in Table 5), probably evoking such previous experiences.

\section{Discussion and conclusions}

The findings presented above confirmed that, indeed, DIMs can foster lower-achieving students' explorative participation in mathematical discourse. Moreover, the findings exceeded my expectations in the degree to which they confirmed my conjecture about how this might occur. Indeed, Gal and Sun identified DIMs with which they were familiar enough to engage 
in discourse about them, making them the protagonists of their meaningful narrative. This fostered a much more objectified and explorative discourse than that of their peers.

There is more. Not only was the focal dyad's discourse more explorative than the background dyad's, but it also succeeded in reaching a meaningful response where the higher-achieving dyad did not. Why? Let me present a possible answer, which, although certainly speculative, is plausible and as such worth giving some serious thought. In a traditional classroom, such as that of the background dyad, where algebra is often taught as a fixed set of procedures to carry out in response to precise prompts, students are pushed to develop and stick to ritualistic forms of participation (Boaler \& Greeno, 2000; Sfard, 2017) even though they might have preferred more explorative forms of participation: following their numerous failed and unsupported attempts to construct meaningful mathematical narratives, they resign themselves to the need to just memorize unconnected procedures. Ritualistic participation, while cumbersome and certainly frustrating, can nevertheless suffice to lead the students to where they need to get: to a reasonable success on all kinds of tests and examinations. Mar and Emi's ritualized discourse was evidently sufficient to ensure their relatively high grades. In contrast, judging from Gal's constant quest for a meaningful story, rituals were probably not anything he would be able, or even just willing, to perform. This might be the main reason for his repeated previous failure in such classrooms. Gal's need for meaningfulness could not be compromised.

The conjecture, therefore, that I hereby submit to the reader is this: The fact that Gal opted out from mathematics until his second year of high school may be the result of various factors that include, on the one hand, insufficient support for the sense-making activity he strived for and, on the other hand, his own unwillingness or inability to act in a ritualistic manner. In other words, these two factors, surely related also to identity issues that would have to be studied in depth to test this conjecture (e.g., Heyd-Metzuyanim, 2013, 2015), led Gal to become a victim of his own uncompromising quest for explorative participation. This hypothesis, which should be further explored, is in line with other studies that have unearthed some high-achieving students' awareness and discomfort of belonging to highly ritualistic classrooms settings (Boaler \& Greeno, 2000). It is possible that while the high-achieving students in such studies were able to adapt and consent to perform rituals without making sense of them, some students like Gal are not able or willing to make such a compromise.

Reasoning along these lines, and simplifying, I could generalize and say that students can strive to participate in more explorative or more ritualistic ways. Of course, as noted earlier, these two forms of discourse are at the extremes of a continuum of possibilities, and students' discourse should probably be described as being more directed towards one extreme or the other. But since it is probably a universal human need to be able to make sense of whatever situation one finds herself in, the wish to participate in mathematical discourses in an explorative way may be the default state of matters for most people. If students nevertheless continue to participate in mostly ritualistic ways, ${ }^{3}$ this must be their reaction to some special circumstance. In other words, something must have happened to the students in the past in a given context to disable their explorative attempts (I said "in a given context," because ritualistic participation is probably also context-dependent). They turned to ritualistic participation in mathematics because it gave them a chance to get where they wanted to be. Indeed, it is often possible to pass mathematics examinations drawing on pure rituals and suspending sense-making processes.

\footnotetext{
${ }^{3}$ I said "continue to participate" because according to the Theory of Commognition, some ritualistic participation is initially necessary in order to become acquainted with mathematical discourse in the first place
} 
In my story, I conjecture that learning to talk about DIMs is something that can open new doors into mathematical discourse for students like Gal (and probably also many others): It encourages explorative engagement by allowing identification of the abstract objects about which their mathematical stories are to be told (this, as opposed to stories about concrete objects, such as a mere strings of symbols) and by allowing them to create realizations that they can interact with and talk about in meaningful ways. Aware of those objects and of ways to make sense of them, I believe that more students, including those who have continued to participate ritualistically, can participate in mathematical discourse exploratively. Indeed, DIMs can provide students with a clear sense of the protagonists for their stories and thus foster sense-making processes in mathematics.

Taking a step back to look at these findings more generally, granting students new possibilities to construct abstract mathematical objects may be key in preventing and overcoming persistent learning difficulties, sometimes even seen as learning "disabilities" (Baccaglini-Frank \& Di Martino, 2019 , in press). Indeed, looking at these phenomena from the commognitive perspective, talking about "disability" is replaced with talking about participation in mathematical discourse and failure to construct abstract mathematical objects (Heyd-Metzuyanim, 2013; Lewis, 2017; Sfard, 2008, 2017). Students with a history of persistent low achievement in mathematics will go on "talking mathematics" without, in fact, knowing what they are talking about and without being unable to align their discourse with that of their classmates or the teacher (Heyd-Metzuyanim, 2013; Lewis, 2017). So, persistent low achievement, or even failure, in mathematics becomes a matter of remaining excluded from full-fledged explorative participation in mathematical discourse (e.g., Heyd-Metzuyanim et al., 2016). This study shows in fine-grained detail how DIMs can grant students, including those with a history of low achievement, the possibility of explorative participation in mathematical discourse by helping them find protagonists for their stories.

Although I only presented four students' answers to a single interview question, the findings from the rest of the data collected for this study show similar patterns. Supported by theoretical considerations, I believe that these results are neither limited to the case of Gal and Sun, nor only to those with a history of low achievement, and I hope that future research will explore their generality.

Supplementary Information The online version contains supplementary material available at https://doi.org/ 10.1007/s10649-020-10009-w.

Acknowledgments I would like to express special gratitude to Anna Sfard for her patience and perseverance in supporting the research behind this paper, as well as for the illuminating conversations about its drafts. I also wish to thank all the participants of this study, without whom none of this would have been possible.

Funding Open access funding provided by Università di Pisa within the CRUI-CARE Agreement.

Open Access This article is licensed under a Creative Commons Attribution 4.0 International License, which permits use, sharing, adaptation, distribution and reproduction in any medium or format, as long as you give appropriate credit to the original author(s) and the source, provide a link to the Creative Commons licence, and indicate if changes were made. The images or other third party material in this article are included in the article's Creative Commons licence, unless indicated otherwise in a credit line to the material. If material is not included in the article's Creative Commons licence and your intended use is not permitted by statutory regulation or exceeds the permitted use, you will need to obtain permission directly from the copyright holder. To view a copy of this licence, visit http://creativecommons.org/licenses/by/4.0/. 


\section{References}

Antonini, S., Baccaglini-Frank, A., \& Lisarelli, G. (2020). From experiences in a dynamic environment to written narratives on functions. Digital Experiences in Mathematics Education, 6, 1-29. https://doi.org/10.1007/ s40751-019-00054-3

Artigue, M. (2002). Learning mathematics in a CAS environment: The genesis of a reflection about instrumentation and the dialectics between technical and conceptual work. International Journal of Computers for Mathematical Learning, 7, 245-274. https://doi.org/10.1023/A:1022103903080

Arzarello, F., Olivero, F., Paola, D., \& Robutti, O. (2002). A cognitive analysis of dragging practices in Cabri environments. ZDM Mathematics Education, 34(3), 66-72.

Baccaglini-Frank, A. (2019). Dragging, instrumented abduction and evidence in processes of conjecture generation in a DGE. ZDM Mathematics Education, 51(5), 779-791. https://doi.org/10.1007/s11858-019-01046-8

Baccaglini-Frank, A., \& Di Martino, P. (2019). Mathematical learning difficulties and dyscalculia. In S. Lerman (Ed.), Encyclopedia of mathematics education (living ed.). Springer International Publishing AG. https://doi. org/10.1007/978-3-319-77487-9

Baccaglini-Frank, A., \& Di Martino, P. (in press). Socio-cultural differences and sensitivities in the mathematics classroom. In D. Lucangeli (Ed.), Understanding dyscalculia (pp. 120-149). New York, NY: Routledge.

Baccaglini-Frank, A., \& Mariotti, M. A. (2010). Generating conjectures in dynamic geometry: The maintaining dragging model. International Journal of Computers for Mathematical Learning, 15, 225-253. https://oi. org/10.1007/s10758-010-9169-3

Baccaglini-Frank, A., \& Poli, F. (2015). Migliorare l'apprendimento. Percorso per l'insegnamento in presenza di BES al primo biennio della scuola secondaria di secondo grado. Novara, Italy: DeAgostini Scuola.

Boaler, J., \& Greeno, J. G. (2000). Identity, agency and knowing in mathematics worlds. In J. Boaler (Ed.), Multiple perspectives on mathematics teaching and learning (pp. 171-200). London, UK: Ablex publishing.

Carlson, M. P. \& Oehrtman, M. (2005). Key aspects of knowing and learning the concept of function. Research Sampler 9. MAA. https://www.maa.org/programs/faculty-and-departments/curriculum-departmentguidelines-recommendations/teaching-and-learning/9-key-aspects-of-knowing-and-learning-the-concept-offunction

Geraniou, E., \& Jankvist, U. (2019). Towards a definition of "mathematical digital competency". Educational Studies in Mathematics, 102, 29-45. https://doi.org/10.1007/s10649-019-09893-8

Goldenberg, E. P., Lewis, P., \& O'Keefe, J. (1992). Dynamic representation and the development of an understanding of functions. In G. Harel \& E. Dubinsky (Eds.), The concept of function: Aspects of epistemology and pedagogy, 25. MAA Notes

Healy, L., \& Sinclair, N. (2007). If this is our mathematics, what are our stories? International Journal of Computers for Mathematical Learning, 12(1), 3-21. https://doi.org/10.1007/s10758-006-9109-4

Hegedus, S., \& Tall, D. (2016). Foundations for the future: The potential of multimodal technologies for learning mathematics. In L. D. English \& D. Kirshner (Eds.), Handbook of international research in mathematics education (3rd ed.pp. 543-562). New York, NY: Routledge.

Heyd-Metzuyanim, E. (2013). The co-construction of learning difficulties in mathematics - Teacher-student interactions and their role in the development of a disabled mathematical identity. Educational Studies in Mathematics, 83(3), 341-368. https://doi.org/10.1007/s10649-012-9457-z

Heyd-Metzuyanim, E. (2015). Vicious cycles of identifying and mathematizing: A case study of the development of mathematical failure. Journal of the Learning Sciences, 24(4), 504-549. https://doi.org/10.1080/ 10508406.2014.999270

Heyd-Metzuyanim, E., Tabach, M., \& Nachlieli, T. (2016). Opportunities for learning given to prospective mathematics teachers: Between ritual and explorative instruction. Journal of Mathematics Teacher Education, 19(6), 547-574. https://doi.org/10.1007/s10857-015-9311-1

Hollebrands, K., \& Okumus, S. (2018). Secondary mathematics teachers' instrumental integration in technologyrich classrooms. The Journal of Mathematical Behavior, 49, 82-94. https://doi.org/10.1016/j.jmathb.2017. 10.003

Hourcade, J. P., Bullock-Rest, N. E., \& Hansen, T. E. (2012). Multitouch tablet applications and activities to enhance the social skills of children with autism spectrum disorders. Personal and Ubiquitous Computing, 16(2), 157-168. https://doi.org/10.1007/s00779-011-0383-3

Lavie, I., Steiner, A., \& Sfard, A. (2019). Routines we live by: From ritual to exploration. Educational Studies in Mathematics, 101, 153-176. https://doi.org/10.1007/s10649-018-9817-4

Leung, A., \& Baccaglini-Frank, A. (2017). Digital technology in designing mathematics education tasks potential and pitfalls. Mathematics education in the digital era: Springer.

Leung, A., Baccaglini-Frank, A., \& Mariotti, M. A. (2013). Discernment in dynamic geometry environments. Educational Studies in Mathematics, 84(3), 439-460. https://doi.org/10.1007/s10649-013-9492-4 
Lewis, K. E. (2017). Designing a bridging discourse: Re-mediation of a mathematical learning disability. Journal of the Learning Sciences, 26(2), 320-365. https://doi.org/10.1080/10508406.2016.1256810

Lisarelli, G. (2019). A dynamic approach to functions and their graphs: A study of students' discourse from a commognitive perspective. University of Firenze, Firenze, Italy: Doctoral dissertation Retrieved from: https://flore.unifi.it/handle/2158/1152055\#.X2dmIC8Rp24

Nachlieli, T., \& Tabach, M. (2012). Growing mathematical objects in the classroom - The case of function. International Journal of Educational Research, 51-52, 10-27. https://doi.org/10.1016/j.ijer.2011.12.007

$\mathrm{Ng}, \mathrm{O}$. (2016). Comparing calculus communication across static and dynamic environments using a multimodal approach. Digital Experiences in Mathematics Education, 2(2), 115-141. https://doi.org/10.1007/s40751016-0014-8

Palmas, S., Rojano, T., \& Sutherland, R. (2020). Digital technologies as a means of accessing powerful mathematical ideas. A study of adults with low schooling in Mexico. Teaching Mathematics and its Applications: An International Journal of the IMA. Advance access publication https://doi.org/10.1093/ teamat/hraa004

Robotti, E. (2017). Designing innovative learning activities to face up to difficulties in algebra of dyscalculia students: How exploit the functionality of AlNuSet. In A. Baccaglini-Frank \& A. Leung (Eds.), Digital technologies in designing mathematics education tasks-Potential and pitfalls, (pp. 193-214). Springer.

Robotti, E. \& Baccaglini-Frank, A. (2017). Using digital environments to address students' mathematical learning difficulties. In E. Faggiano, F, Ferrara and A. Montone (Eds.), Innovation and technology enhancing mathematics education. Mathematics education in the digital era 10, (pp. 77-106). Springer.

Santi, G., \& Baccaglini-Frank, A. (2015). Possible forms of generalization we can expect from students experiencing mathematical learning difficulties. PNA, Revista de Investigaciòn en Didàctica de la Matemàtica, 9(3), 217-243.

Sfard, A. (2008). Thinking as communicating: Human development, the growth of discourses, and mathematizing. Cambridge, UK: Cambridge University Press.

Sfard, A. (2017). Ritual for ritual, exploration for exploration. In J. Adler \& A. Sfard (Eds.), Research for educational change: Transforming researchers' insights into improvement in mathematics teaching and learning (pp. 39-63). London, UK: Routledge.

Sfard, A. (2018). Commognition. In S. Lerman (Ed.), Encyclopedia of mathematics education (living ed.). Springer International Publishing AG. https://doi.org/10.1007/978-3-319-77487-9_100031-1

Sfard, A. (2019). Making sense of identities as sense-making devices. ZDM Mathematics Education, 51(3), 555564. https://doi.org/10.1007/s11858-019-01058-4

Sinclair, N., Healy, L., \& Reis Sales, C. (2009). Time for telling stories: Narrative thinking with dynamic geometry. ZDM Mathematics Education, 41(4), 441-452. https://doi.org/10.1007/s11858-009-0180-x

Sinclair, N., \& Heyd-Metzuyanim, E. (2014). Learning number with TouchCounts: The role of emotions and the body in mathematical communication. Technology, Knowledge and Learning, 19, 81-99. https://doi.org/10. 1007/s10758-014-9212-x

Publisher's note Springer Nature remains neutral with regard to jurisdictional claims in published maps and institutional affiliations. 